\title{
Prolactin Prevents Chronic Stress-Induced Decrease of Adult Hippocampal Neurogenesis and Promotes Neuronal Fate
}

\author{
Luz Torner, ${ }^{1,3 *}$ Sandra Karg, ${ }^{1 *}$ Annegret Blume, ${ }^{1}$ Mahesh Kandasamy, ${ }^{2}$ Hans-Georg Kuhn, ${ }^{2}$ Jürgen Winkler, ${ }^{2,4}$ \\ Ludwig Aigner, ${ }^{2,5}$ and Inga D. Neumann ${ }^{1}$ \\ ${ }^{1}$ Department of Behavioral and Molecular Neuroendocrinology, Institute of Zoology and ${ }^{2}$ Department of Neurology, University of Regensburg, 93053 \\ Regensburg, Germany, ${ }^{3}$ Centro de Investigación Biomédica de Michoacán, Instituto Mexicano del Seguro Social, Morelia, Michoacán, 58080, México, \\ ${ }^{4}$ Division of Molecular Neurology, University of Erlangen, 91054 Erlangen, Germany, and ${ }^{5}$ Institute for Molecular Regenerative Medicine, Paracelsus \\ Private Medical University Salzburg, 5020 Salzburg, Austria
}

Chronic exposure to stress results in a reduction of hippocampal neurogenesis and of hippocampal volume. We examined whether prolactin (PRL), a regulator of the stress response and stimulator of neurogenesis in the subventricular zone, influences neurogenesis in the hippocampal dentate gyrus (DG) of chronically stressed adult C57BL/6 male mice. Chronically stressed ( $4 \mathrm{~h}$ daily immobilization for $21 \mathrm{~d}$ ) or nonstressed mice were treated with either ovine PRL or vehicle between days 1-14. BrdU was injected daily between days 1-7 to evaluate cell survival and fate, or twice on day 21 to evaluate cell proliferation. Hippocampal cell proliferation was unchanged by either stress exposure or PRL at the end of the treatments. In contrast, the number of cells in the DG that incorporated BrdU during the first phase of the experiment and survived to the end of the experiment was decreased in vehicle-treated stressed mice compared with PRL- or vehicle-treated nonstressed control mice. Stressed animals receiving PRL had significantly more BrdU-labeled cells than vehicle-treated stressed mice at this time point. Cell fate analysis revealed a higher percentage of neurons in PRL- compared with vehicle-treated stressed mice. The results demonstrate that PRL protects neurogenesis in the DG of chronically stressed mice and promotes neuronal fate.

Key words: hippocampus; cell survival; proliferation; HPA axis; corticosterone; dentate gyrus

\section{Introduction}

The hippocampal dentate gyrus (DG) is one of the germinal areas of neuronal precursors in the adult brain of rodents and humans (Cameron et al., 1993; Kuhn et al., 1996; Eriksson et al., 1998). The generation and removal of newly born cells in the DG is delicately balanced (Biebl et al., 2000) and modulated by a variety of molecular cues (for review, see Lie et al., 2004, Ming and Song, 2005). These processes are altered by environmental factors (Kempermann et al., 1997), during the peripartum period (Leuner et al., 2007), and after brain pathologies (Winner et al., 2004, 2008). Moreover, psychosocial and physical stress impair hippocampal cell proliferation and neurogenesis (Gould et al., 1997; McEwen, 2000; Duman et al., 2001; Pham et al., 2003; Malberg, 2004; Mirescu and Gould, 2006). These detrimental effects of stress have been attributed to glucocorticoids, which are

\footnotetext{
Received July 8, 2008; revised Nov. 6, 2008; accepted Dec. 17, 2008.

This work was supported by the Fondo de Fomento a la Investigación del Instituto Mexicano del Seguro Social (2006/1A///055; L.T.), VolkswagenStiftung (I.D.N.), Deutsche Forschungsgemeinschaft (I.D.N.), and Bundesministerium für Bildung und Forschung (I.D.N.). From our Departments of the University of Regensburg we thank L. Gonzalez and R. Aigner for their excellent technical assistance and Dr. B. Winner for her guidance during the stereological evaluation of hippocampal neurogenesis, and we thank Dr. Parlow and the National Hormone and Peptide Program (National Institute of Diabetes and Digestive and Kidney Diseases-National Institutes of Health) for supplying the ovine prolactin.

*L.T. and S.K. contributed equally to this work.

Correspondence should be addressed to Inga D. Neumann, Institute of Zoology, University of Regensburg, Uni-

versitätsstrasse 31, 93053 Regensburg, Germany. E-mail: inga.neumann@biologie.uni-regensburg.de. DOI:10.1523/JNEUROSCI.3178-08.2009

Copyright $\odot 2009$ Society for Neuroscience $\quad 0270-6474 / 09 / 291826-08 \$ 15.00 / 0$
}

elevated in response to stressor exposure (Gould et al., 1992; Cameron and Gould, 1994).

Prolactin (PRL), primarily known for its hormonal actions, has recently been identified as a neuropeptide of the brain. In addition to its synthesis by adenohypophysial lactotroph cells, PRL expression (Clapp et al., 1994) and local release from neuronal structures occur in several brain regions including the hypothalamus (DeVito et al., 1991; Torner et al., 1995), for example within the paraventricular nuclei (Torner et al., 2004). In addition to neuronal sources of brain PRL, peripheral PRL can cross the blood-brain barrier via receptor-mediated transport in the choroid plexus, and thereby may exert central effects (Walsh et al., 1987; Mangurian et al., 1992).

A variety of behavioral and neuronal actions have been described to be regulated by brain PRL receptors, which exist in long and short forms (Ben-Jonathan et al., 1996; Pi and Grattan, 1998). Such effects include anxiolysis in male and female rats (Torner et al., 2001), attenuation of hormonal and neuronal responses to various stressors (Donner et al., 2007; Torner et al., 2002), regulation of maternal behavior (Bridges et al., 1990), modulation of the electrophysiological properties of oxytocinergic neurons (Kokay et al., 2006) and inhibition of the stress-induced development of gastric ulcer (Fujikawa et al., 2004). Interestingly, the activity of the brain PRL system is elevated in response to stressor exposure (Torner et al., 2004). Furthermore, during the peripartum period expression of PRL and its receptor, as well as neuronal release within the brain, has been shown to be high (Pi and Grattan, 1999; Torner et al., 2002, 2004). 


\section{Proliferation}

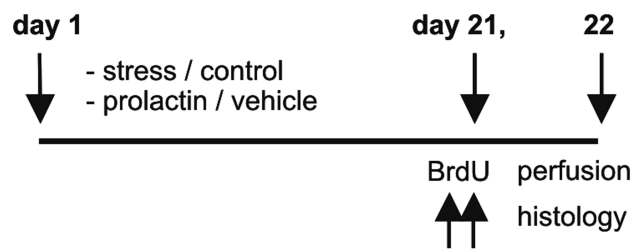

Cell fate

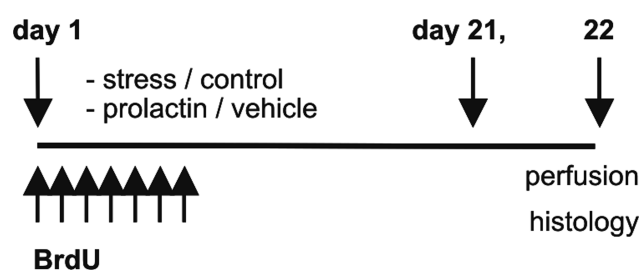

Figure 1. Experimental protocols used to study cell proliferation or survival. To study cell proliferation, mice were subjected to chronic stress ( $4 \mathrm{~h}$ restraint daily from days $1-21$ ) or left undisturbed, received two injections of BrdU (50 mg/kg, i.p.) on day 21, and were perfused on day 22. To study cell fate, chronically stressed or unstressed groups of mice were injected with BrdU on days $1-7$, and perfused on day 22 of chronic stress. Additionally, all groups of mice received a daily subcutaneous injection of PRL ( $8 \mu \mathrm{g} / 100 \mu$ l saline) or vehicle (100 $\mu$ l, sterile $0.9 \%$ saline) from days 1 to 21 (proliferation) or days 1 to 14 (survival).

Recently, PRL has been identified as a regulator of brain cell proliferation, e.g., in astrocytes (DeVito et al., 1992; Mangoura et al., 2000), neuroblastoma cells (Mohammad et al., 2002), oligodendroglial progenitors (Gregg et al., 2007) and neurospheres isolated from the subventricular zone (SVZ) of mice (Shingo et al., 2003). Moreover, peripheral and central administration of PRL (Shingo et al., 2003), or male pheromone-induced PRL release in females (Mak et al., 2007; Larsen et al., 2008), increases adult neurogenesis in the SVZ. In contrast to the SVZ, cell proliferation within the hippocampal DG was not found to be altered by PRL under basal, nonstress conditions (Shingo et al., 2003).

The aim of the present work was to determine whether PRL modulates proliferation and/or cell survival of newborn cells in the hippocampus of chronically stressed rodents. Therefore, we studied PRL effects on cell proliferation, cell survival and neurogenesis in the DG of adult C57BL/6 male mice after exposure to restraint stress ( $4 \mathrm{~h}$ daily) for $21 \mathrm{~d}$. Mice were treated daily with PRL or vehicle during the first $14 \mathrm{~d}$ of stress exposure and the percentage of newly generated neurons in the DG was evaluated.

\section{Materials and Methods}

Animals. Male C57BL/6 mice (Charles River, Sulzfeld, 6 weeks of age) were housed individually under standard laboratory conditions $(12 \mathrm{~h}$ light/dark cycles) and were given ad libitum access to food and water. Mice were randomly assigned to 4 groups: nonstressed/vehicle, nonstressed/PRL, stressed/vehicle, and stressed/PRL (Fig. 1). All experiments were approved by the local Bavarian government and performed in accordance with the Guide for the Care and Use of Laboratory Animals by the National Institutes of Health.

Chronic stress procedure. Animals of the stress groups were subjected to $4 \mathrm{~h}$ restraint for $21 \mathrm{~d}$ starting at 9:00 A.M. daily. Each mouse was placed in a modified $50 \mathrm{ml}$ polyethylene tube fitted with multiple air holes. Nonstressed control mice were left undisturbed in their home cages in the same room. The body weight of each animal was recorded at the beginning and at the end of the stress procedure. Additionally, the thymus and adrenal glands were removed from all animals on day 22 and weighed.

$P R L$ administration. Animals received a daily subcutaneous injection of ovine PRL ( $8 \mu \mathrm{g} / 100 \mu \mathrm{l}$ of sterile $0.9 \% \mathrm{NaCl}$ solution; Sigma) or vehicle (100 $\mu$ l sterile $0.9 \% \mathrm{NaCl}$ solution) between 8:00 and 10:00 A.M. during days 1-21 (cell proliferation), or days 1-14 (cell survival) of the stress procedure. Mice of the stress groups were injected immediately before subjecting them to immobilization.

BrdU labeling. 5-Bromo-2-deoxyuridine (BrdU; Sigma) was prepared in $0.9 \% \mathrm{NaCl}$ solution to a dilution of $20 \mathrm{mg} / \mathrm{ml}$ the same day it was used. To examine the proliferation of precursor cells, mice were injected with BrdU (50 mg/kg, i.p.) at 10:00 A.M. and 8:00 P.M. on day 21 of stressor exposure. To trace the fate of recently born cells, mice received daily injections of $\mathrm{BrdU}(50 \mathrm{mg} / \mathrm{kg}$ ) between 8:00 A.M. and 10:00 A.M. during the first $7 \mathrm{~d}$ of stressor exposure.

Hippocampal cell proliferation. Mice of the chronic stress and control groups received daily injections of either PRL (stress group: $n=7$; nonstress group: $n=8$ ) or vehicle (stress group: $n=8$; nonstress group: $n=$ 8 ) between days 1 and 21 of stress exposure. On day 21, mice received 2 injections of BrdU at 10:00 A.M. and at 8:00 P.M., i.e., 12-24 h before intracardial perfusion (Fig. 1). This time has been reported to be sufficient for newborn cells to complete one cell cycle (Takahashi et al., 1992). On day 22 , the animals were anesthetized with pentobarbital $(1.2 \mathrm{~g} / \mathrm{kg}$ bw; Narcoren, Merial) and intracardially perfused with paraformaldehyde between 8:00 A.M. and 10:00 A.M. Adrenal and thymus weights were recorded.

Fate of newly generated hippocampal cells. Mice from the chronic stress and control groups received BrdU daily between 8:00 A.M. and 10:00 A.M. during the first $7 \mathrm{~d}$, and were administered PRL (stress group: $n=$ 7; nonstress group: $n=8$ ) or vehicle (stress group: $n=8$; nonstress group: $n=8$ ) between days 1 and 14 of chronic stress exposure (Fig. 1). On day 22, the animals were anesthetized as described above and intracardially perfused with paraformaldehyde. Adrenal and thymus weights were recorded.

Analysis of plasma corticosterone. Groups of chronically stressed and nonstressed mice were treated daily with PRL or vehicle $(n=6$ for each group) as described above. On days $4,8,15$, and 22, between 8:00 A.M. and 10:00 A.M., i.e., $\sim 18-20 \mathrm{~h}$ after termination of the last immobilization exposure, trunk blood was collected into EDTA-coated Eppendorf tubes containing $10 \mu \mathrm{l}$ Trasylol (Bayer) and centrifuged $\left(4000 \mathrm{rpm}, 4^{\circ} \mathrm{C}\right.$, $5 \mathrm{~min}$ ). Plasma samples were stored at $-20^{\circ} \mathrm{C}$ for analysis of plasma corticosterone using a commercially available radioimmunoassay (ICN).

Histological procedures. Animals were perfused intracardially with 4\% paraformaldehyde in $0.1 \mathrm{~m}$ phosphate buffer, $\mathrm{pH}$ 7.4. Brains were postfixed overnight at $4^{\circ} \mathrm{C}$ and stored in $30 \%$ sucrose. Brain sections $(40 \mu \mathrm{m})$ were cut sagitally using a sliding microtome (Leica), and subsequently stored at $4^{\circ} \mathrm{C}$ in cryoprotectant solution (glycerol, ethylene glycol and 0.1 м PB, pH 7.4, 1:1:2 by volume). Immunostaining of BrdU-labeled cells was performed on free-floating sections using the diaminobenzidine (DAB) peroxidase method. Briefly, brain sections were treated with $0.6 \%$ $\mathrm{H}_{2} \mathrm{O}_{2}$ in Tris-buffered saline (TBS: $0.15 \mathrm{M} \mathrm{NaCl}, 0.1 \mathrm{~m}$ Tris-HCl, $\mathrm{pH}$ 7.5) for $30 \mathrm{~min}$. For DNA denaturation, sections were incubated for $2 \mathrm{~h}$ in $50 \%$ formamide $/ 2 \times$ saline-sodium citrate (SSC) $(0.3 \mathrm{M} \mathrm{NaCl}, 0.03 \mathrm{M}$ sodium citrate) at $65^{\circ} \mathrm{C}$, rinsed for $5 \mathrm{~min}$ in $2 \times \mathrm{SSC}$, incubated in $2 \mathrm{M} \mathrm{HCl}$ for $30 \mathrm{~min}$ at $37^{\circ} \mathrm{C}$ and washed for $10 \mathrm{~min}$ in $0.1 \mathrm{~m}$ boric acid, $\mathrm{pH}$ 8.5. Thereafter, sections were incubated in TBS/ $0.25 \%$ Triton-X/3\% normal donkey serum for $30 \mathrm{~min}$, followed by incubation with the primary rat $\alpha$-BrdU antibody (1:500, Oxford Biotechnology) in TBS/donkey serum overnight at $4^{\circ} \mathrm{C}$. The next day, the sections were incubated with biotinylated secondary rabbit $\alpha$-rat antibodies (1:1000, Dianova), followed by the avidin-biotin-peroxidase complex reaction (1 h; ABC system, Vector Laboratories). Thereafter, the signal was visualized using DAB (25 $\mathrm{mg} / \mathrm{ml}$ in water with $0.01 \% \mathrm{H}_{2} \mathrm{O}_{2}, 0.04 \% \mathrm{NiCl}_{2}$ ).

Stereology. To determine the number of BrdU-positive cells, every sixth section ( $240 \mu \mathrm{m}$ interval) of the left brain hemispheres was examined for BrdU-positive cells throughout the rostral caudal extent of the granule cell layer and the adjacent subgranular zone, defined as a two cells-wide area between the border of the hilus and the granular zone. Cells were counted regardless of shape or size under $40 \times$ magnification. The total number of BrdU-positive cells was multiplied by a factor of 6 . We used a semiautomatic stereology system (Stereoinvestigator, MicroBrightField) and a $5 \times$ objective to trace the area of the DG/SGZ. The volume was determined by adding up the traced areas of each brain and multiplying them by the intersection distance $(240 \mu \mathrm{m})$. To determine 
the density of BrdU-positive cells in the examined area, we related the number of BrdU-positive cells to the DG volume.

Immunofluorescence staining and confocal analysis. For epifluorescence immunodetection, free-floating sections were washed extensively in TBS $(0.15 \mathrm{~m} \mathrm{NaCl}, 0.1 \mathrm{~m}$ Tris-HCl, $\mathrm{pH}$ 7.5), then blocked with a solution composed of TBS, $0.1 \%$ Triton X-100, $1 \%$ bovine serum albumin, and $0.2 \%$ Teleostean gelatin (fish gelatin buffer; Sigma). The identical solution was used during the incubations with primary/secondary antibodies. Primary antibodies were applied overnight at $4^{\circ} \mathrm{C}$. Fluorochromeconjugated species-specific secondary antibodies were used for immunodetection. Sections were put on Superfrost Plus slides (MenzelGläser) and mounted in Prolong Antifade kit (Invitrogen). Epifluorescence observation was performed with a confocal scanning laser microscope (Leica; TCS-NT).

The following antibodies and final dilutions were used. Primary antibodies: rat $\alpha$-BrdU 1:500 (Oxford Biotechnology), mouse $\alpha$-neuronal (NeuN) 1:500 (Millipore Bioscience Research Reagents), rabbit $\alpha$-glial fibrillary acidic protein (GFAP) 1:1000 (Dako). Secondary antibodies: donkey $\alpha$-mouse, $\alpha$-rabbit or $\alpha$-rat conjugated with fluorescein cy 5 (Jackson Immuno Research) Alexa Fluor 488 (Invitrogen) or rhodamine $\mathrm{X}$ (Dianova), respectively.

Counting procedures. All morphological analyses were performed on blind coded slides. To determine the frequency of neuronal differentiation of newborn cells, a series of every sixth section ( $240 \mu \mathrm{m}$ interval) was examined using the confocal laser microscope equipped with a $40 \times$ Plan Apochromat oil objective (1.25 numeric aperture; Zeiss) and a pinhole setting that corresponded to a focal plane of $2 \mu \mathrm{m}$ or less. On average, 50 BrdU-labeled cells per animal were analyzed for neuronal differentiation. BrdU-positive cells were counted as solely BrdU-positive (newborn cells), BrdU/NeuN double-positive cells (newborn neurons) and BrdU/ GFAP (newborn astrocytes) double-positive cells.

Analysis of hippocampal PRL receptors by Western blots. Groups of stress and control mice ( $n=5$ per group) were killed $14 \mathrm{~d}$ after daily administration of PRL or vehicle as described above. On day 14, mice received the last dose of PRL, before they were exposed to $1 \mathrm{~h}$ of restraint and subsequently killed. Hippocampi were dissected and collected on dry ice. Membrane proteins were extracted with lysis buffer (50 mм Tris, 1 mм EDTA, $150 \mathrm{~mm} \mathrm{NaCl,} \mathrm{0.1 \%} \mathrm{Triton} \mathrm{X-100,} 1$ mg/ml Trasylol, 100 $\mu \mathrm{g} / \mathrm{ml}$ PMSF). The proteins were separated on a $12 \%$ SDS-PAGE and subsequently blotted onto a nitrocellulose membrane. The long and short PRL receptor isoforms were detected using a monoclonal antibody (1:1000, MA1-610, U5, Affinity Bioreagents). Anti- $\beta$-tubulin (1:5000, Sigma-Aldrich) was used as loading control. The signal was enhanced with a secondary antibody (sheep-anti-mouse, 1:1000, Amersham Biosciences) and visualized using enhanced chemiluminescence (Western blotting analysis system, Amersham Biosciences).

Statistical analysis. All numerical data were expressed as the mean \pm SEM and were statistically analyzed using Microsoft Excel (Office XP) and GB-Stat 6.0 (Dynamic Microsystems). Statistical significance was determined using a two- (factors: stress $\times$ treatment) or three-way (factors stress $\times$ treatment $\times$ time) ANOVA followed by Student-NewmanKeuls post hoc test. Data were considered significant at $p<0.05$.

\section{Results \\ No effect of chronic stress and/or PRL on hippocampal cell proliferation}

To reveal effects of PRL on cell proliferation, hippocampal volume or cell density in the DG of stressed and nonstressed mice, the number of BrdU-positive cells was assessed after $21 \mathrm{~d}$ of chronic stress and $1 \mathrm{~d}$ of BrdU application (Fig. 1). In contrast to studies in rats where repeated exposure to immobilization stress (Pham et al., 2003) or to chronic unpredictable stress (Heine et al., 2004) reduced new cell proliferation in the DG, our quantitative analysis did not reveal any significant effects of chronic stress or of PRL treatment on DG cell proliferation (Fig. 2) or on cell density and DG volume (data not shown).

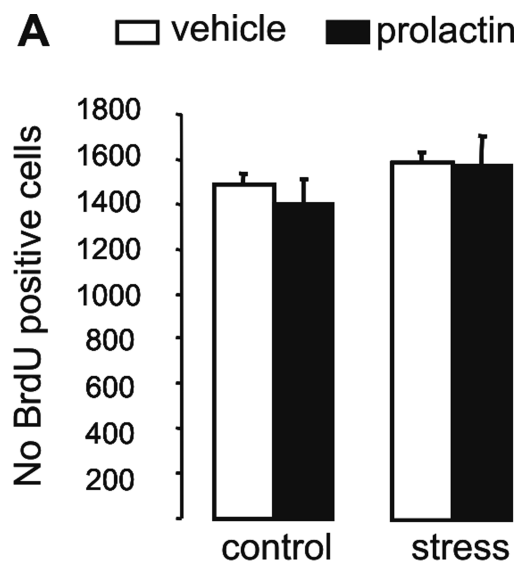

B

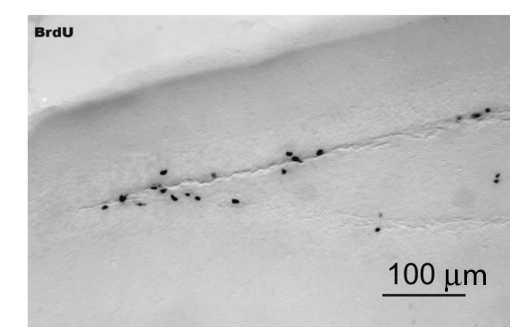

Figure 2. Effects of chronic stress and subcutaneous PRL treatment on cell proliferation within the DG. $\boldsymbol{A}$, Daily immobilization over $21 \mathrm{~d}$ or PRL treatment did not change proliferation rate. Numbers in parentheses give group size. $\boldsymbol{B}$, Picture illustrates BrdU-staining of the DG. Scale bar, $100 \mu \mathrm{m}$.

\section{Hippocampal neurogenesis is impaired by chronic stress and} rescued by PRL treatment

Next, we analyzed the effects of chronic stress and subcutaneous PRL on the fate of newly generated hippocampal cells. Stereological estimations of the number of BrdU-labeled cells present in the granular and subgranular zones of the hippocampal DG $22 \mathrm{~d}$ after starting the $7 \mathrm{~d}$ of BrdU injection showed significant effects of stress and PRL treatment (factors stress $\times$ treatment $F_{(1,29)}=$ 4.37, $p=0.04)$. In vehicle-treated mice, daily exposure to restraint significantly reduced the number of BrdU-labeled cells in the DG compared with vehicle- and PRL-treated control mice $(p<0.01)$ (Fig. 3A). Importantly, PRL treatment prevented the chronic stress-induced decrease in the number of BrdU-labeled cells in the DG. The number of BrdU-labeled cells was significantly higher in the stressed-PRL compared with the stressedvehicle group $(p<0.05)$ and was not statistically different from both nonstressed controls (Fig. 3A).

No significant differences were observed in the volume of the DG among the groups (Fig. 3B). However, the effect of PRL treatment on cell fate was confirmed by the calculation of hippocampal cell density which was found to differ between the groups (stress $\times$ treatment $F_{(1,26)}=8.84, p=0.006$ ) (Fig. 3C). Density of BrdU-labeled cells in the DG was reduced in vehicle-treated stressed mice compared with vehicle-treated nonstressed animals $(p<0.01)$. PRL treatment prevented the stress-induced decrease in cell density, as cell density was significantly higher in the PRLtreated stressed group compared with the vehicle-treated stressed group $(p<0.05)$ (Fig. $3 C$ ). Again, the cell density in the PRLtreated stressed group did not differ statistically from the control groups of mice. 


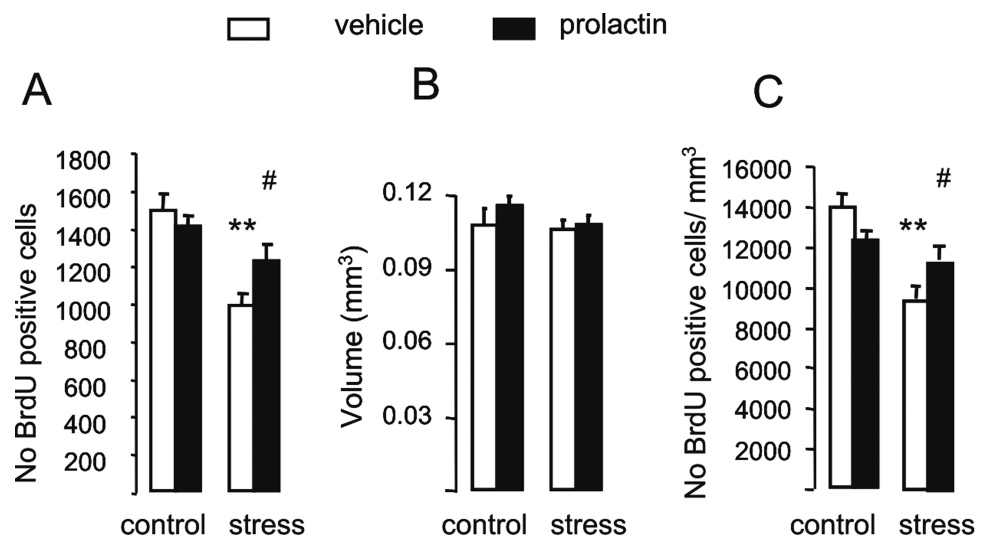

Figure 3. Effects of chronic stress and subcutaneous PRL on cell survival $(\boldsymbol{A})$, hippocampal volume $(\boldsymbol{B})$, and cell density of the hippocampal DG (C). Daily immobilization (restraint, $21 \mathrm{~d}, 4 \mathrm{~h} / \mathrm{d}$ ) decreased cell survival $(\boldsymbol{A})$ and cell density $(\boldsymbol{C})$, in vehicle-treated mice $(p<0.01)$. PRL treatment prevented the stress-induced decrease in both cell survival and cell density $(p<0.05)$. Results are mean \pm SEM. ${ }^{* *} p<0.01$ versus vehicle- and PRL-control groups; ${ }^{*} p<0.05$ versus vehicle-stress group.

indirect mechanism, hippocampal tissue was analyzed for the presence of PRL receptors.

Western blot analysis of hippocampal extracts revealed the presence of two immunoreactive bands with molecular weights of 100 and $40 \mathrm{kDa}$, corresponding to the reported long and short isoforms of the PRL receptor, respectively (Fig. 5). The presence of hippocampal PRL receptors was found in stressed and nonstressed mice independent of treatment. This suggests that PRL could exert specific and direct effects on these cells.

\section{PRL does not affect chronic}

stress parameters

To further substantiate the possibility of a direct effect of PRL on the hippocampal tissue, the possibility was excluded that

\section{Chronic stress and PRL effects on cell differentiation of newly generated cells in the DG}

To monitor the fate of the newly born cells in the hippocampal DG during chronic stress and under the influence of PRL treatment, BrdU-labeled cells were characterized by their expression of either NeuN or astroglial (GFAP) markers. Immunofluorescence triple labeling using antibodies against BrdU, NeuN and GFAP revealed effects of stress and/or PRL treatment on the percentage of cells maturing into neurons (factor treatment: $F_{(1,27)}=$ 2.12, $p=0.15$; factor stress: $F_{(1,27)}=43.3, p<0.0001$; factors treatment $\times$ stress: $F_{(1,27)}=23.6, p<0.0001$ ) or glia (factor treatment: $F_{(1,27)}=1.09, p=0.30$; factor stress: $F_{(1,27)}=22.3, p<$ 0.0001; factors treatment $\times$ stress: $F_{(1,27)}=1.24, p=0.27$ ) (Fig. 4). The percentage of double-labeled BrdU/NeuN cells was significantly lower in vehicle-treated stressed $(87.7 \%)$ compared with vehicle-treated nonstressed $(93.3 \%)$ mice $(p<0.01)$, indicating a reduction of neurogenesis due to chronic stress exposure (Fig. $4 A$ ). In contrast, PRL treatment resulted in a higher percentage of newborn neurons, i.e., double-labeled BrdU/NeuN cells, in the DG of stressed mice $(97.7 \%)$ compared with the vehicle-treated stressed mice $(87.7 \%, p<0.01)$. Moreover, after PRL treatment in stressed mice, the percentage of BrdU/NeuN cells was higher $(97.7 \%)$ than those of both PRL- $(95.0 \%)$ and vehicle- $(93.3 \%)$ treated nonstressed mice $(p<0.01)$ (Fig. $4 A)$. Less than $10 \%$ of the BrdU-labeled cells displayed GFAP staining in vehicle-treated nonstressed $(5.25 \%)$ or vehicle-treated (7.50\%) stressed mice (Fig. $4 \mathrm{~B}$ ). In PRL-treated mice, the percentage of BrdU/GFAP cells was reduced independently of stress exposure $(p<0.05)$, with significant differences found between vehicle-treated and PRL-treated stressed mice $(p<0.01)$ (Fig. $4 B)$. Thus, PRL either promoted neuronal fate, or enhanced neuronal survival in the DG under stress conditions. Confocal images of double-labeled BrdU/NeuN or BrdU/GFAP cells are depicted in Figure $4 C$.

\section{PRL receptors are expressed in the hippocampus}

PRL stimulates proliferation of neural stem cells and adult neurogenesis in the SVZ (Shingo et al., 2003; Mak et al., 2007; Larsen et al., 2008). In contrast, cell proliferation within the hippocampal DG is not altered by PRL under basal, nonstress conditions (Shingo et al., 2003). However, our data demonstrate that PRL has a protective effect on neurogenesis under stress conditions. To test whether this effect might be mediated via a direct or
PRL affects established parameters of chronic stress in mice including changes in body, thymus and adrenal glands weight (Reber et al., 2006). Daily exposure to restraint stress altered body weight gain (factor stress: $F_{(1,26)}=29.1, p<0.0001$ ) independent of treatment with either PRL or vehicle (factor treatment: $F_{(1,26)}$ $=0.32, p=0.57$ ). The body weight gain of stressed mice compared with nonstressed controls was reduced between experimental days 1 and $22(p<0.01)$ (Fig. 6A). Effects of chronic stress were also seen in thymus $\left(F_{(1,29)}=19.2, p=0.0002\right)$ and adrenal $\left(F_{(1,29)}=21.4, p<0.0001\right)$ weights independent of treatment. Both vehicle- and PRL-treated stressed mice had reduced thymus weights compared with their respective nonstressed controls $(p<0.05)$ (Fig. $6 C$ ). The opposite effect was seen in adrenal weights, which were significantly increased in both vehicle- $(p<$ $0.01)$ and PRL $(p<0.05)$-treated stressed mice to a similar extend (Fig. 6B). Plasma corticosterone concentrations as estimated $\sim 18-20 \mathrm{~h}$ after termination of the preceding immobilization exposure were significantly elevated on day 4 of chronic stress (factor stress: $F_{(1,23)}=5.51, p=0.02$ ) (Fig. 6D) independent of subcutaneous PRL treatment (interaction stress $X$ treatment: $\left.F_{(1,23)}=0.17, p=0.68\right)$. Also, plasma corticosterone was found to be similar in vehicle- and PRL-treated stressed mice on days $8,15,22$, again estimated $18-20 \mathrm{~h}$ after restraint exposure. These data indicate that stress-related parameters were not influenced by subcutaneous PRL treatment.

\section{Discussion}

Our results provide evidence that PRL rescues adult hippocampal neurogenesis during chronic stress exposure. Repeated peripheral administration of PRL to adult mice during the first 2 weeks of chronic stress resulted in a higher number of newly generated cells detected 3 weeks after the first exposure to stress. Different mechanisms might account for this activity: PRL might (1) counteract the antiproliferative effects of glucocorticoids that most likely inhibit neural progenitor proliferation during the first days of stress, (2) promote neuronal fate and differentiation, and/or (3) promote the survival of newly generated cells after continuous stress exposure.

High concentrations of glucocorticoids inhibit the proliferation of granule cell precursors (Gould et al., 1992; Cameron and Gould, 1994), as well as neuronal survival (Czéh et al., 2002). The inhibitory effects of chronic stress on neurogenesis, including neural cell proliferation and survival in the hippocampus, have 

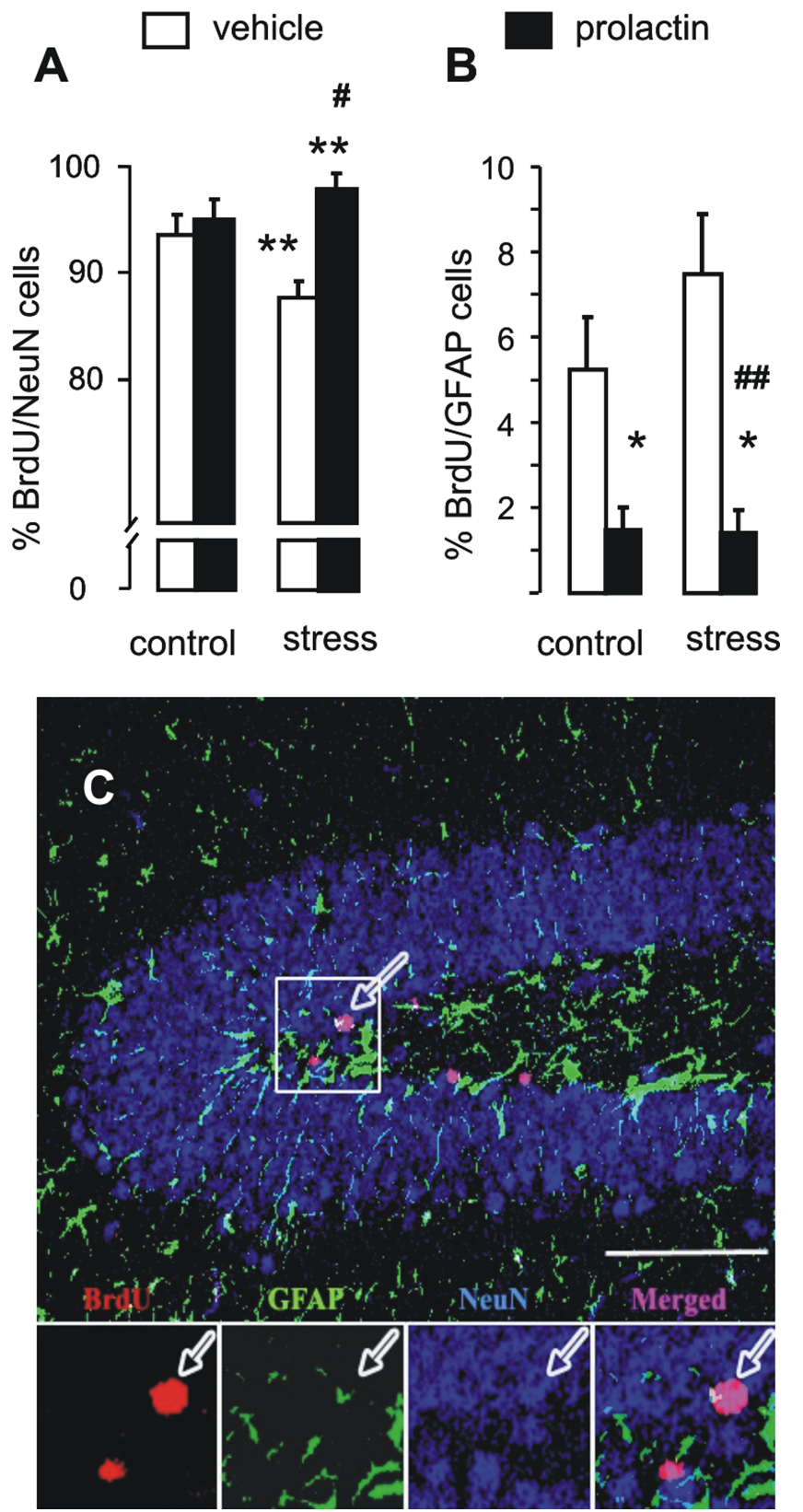

Figure 4. Effects of chronic stress and subcutaneous PRL on different cell populations in the hippocampal DG. Twenty one days after the first BrdU injection, $>90 \%$ of the BrdU-labeled cells matured into granule neurons and expressed $\operatorname{NeuN}(A, C)$. Stress exposure decreased the percentage of NeuN-labeled cells in vehicle-treated $(p<0.001)$, but not in PRL-treated mice. In contrast, a small amount of the BrdU-labeled cells developed into astroglia, expressing GFAP, without differences between control- and stress-vehicle groups $(\boldsymbol{B})$. PRL treatment decreased the percentage of glial cells in both control $(p<0.05)$ and stressed $(p<0.01)$ groups of mice, compared with their respective vehicle-treated group. Results are mean \pm SEM. ${ }^{*} p<0.05$, ${ }^{* *} p<0.01$ ( $n=7$ or 8 animals per group). C, Surviving cells in the adult mouse dentate gyrus $22 \mathrm{~d}$ after daily immobilization express mature neuronal or glial markers. BrdU, Single confocal plane of BrdU-labeled cells in the DG in a section colabeled for the neuronal marker NeuN and the glial marker GFAP. NeuN, Single confocal plane of NeuN-labeled cells in the DG in a section that was colabeled for BrdU and GFAP. GFAP, Single confocal plane of GFAP-labeled cells in the $D G$ in a section that was colabeled for BrdU and NeuN. Merged, Single confocal plane of the same cells, showing colocalization of BrdU, NeuN, and GFAP. Inset, Magnification of a selected region.

clearly been linked to the level of glucocorticoids within the intact DG, as confirmed in rats (Tanapat et al., 2001; Pham et al., 2003), tree shrews (Gould et al., 1997; Lucassen et al., 2001) and marmosets (Gould et al., 1998). However, the effects of stress expo-
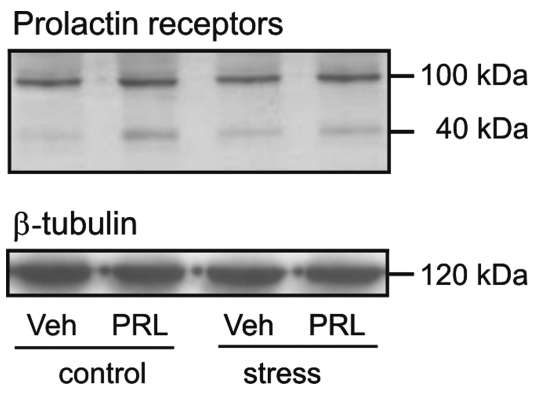

Figure 5. Expression of both long and short isoforms of PRL receptors in hippocampal cells. Hippocampal protein extracts of control and stressed animals treated with vehicle or PRL were subjected to SDS-PAGE and blotted onto a nitrocellulose membrane. Molecular weight markers are depicted on the right, indicating the position of the long ( $100 \mathrm{kDa}$ ) and the short (40 kDa) PRL receptor isoforms. $\beta$-Tubulin was included as loading control. vehicle

A

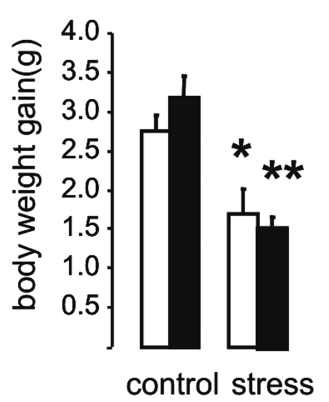

C

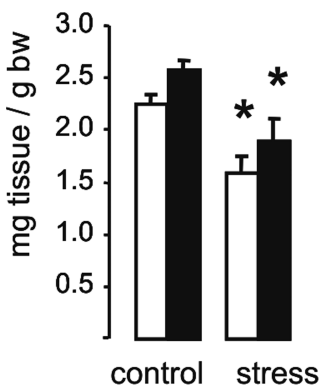

prolactin

B

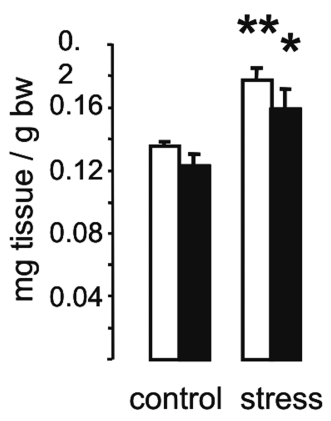

D

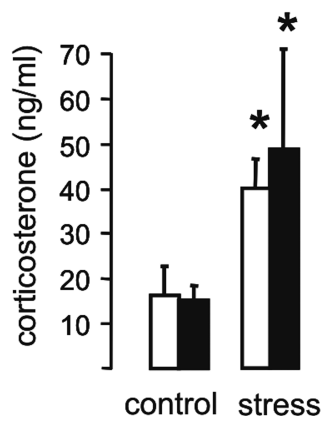

Figure 6. Effects of exposure to chronic stress (restraint, $21 \mathrm{~d}, 4 \mathrm{~h} / \mathrm{d}$ ) on body weight gain $(\boldsymbol{A})$, adrenal weight $(\boldsymbol{B})$, thymus weight $(\boldsymbol{C})$, and plasma corticosterone concentrations in trunk blood ( $\boldsymbol{D}$; day 4 ) in daily vehicle- $(n=8 / 8 / 6)$ and subcutaneous PRL-treated $(n=8 / 7 / 6)$ male mice. Blood samples were taken on day 4 of chronic stress $18 \mathrm{~h}$ after last restraint. Results are mean \pm SEM. ${ }^{* *} p<0.01,{ }^{*} p<0.05$ versus unstressed control group.

sure on hippocampal cell proliferation are strongly dependent on the quality and/or intensity of the stressor, the frequency of stressor exposure, and the species studied. For instance, chronic mild stress decreased cell survival without altering proliferation of newborn cells in the adult rat hippocampus (Lee et al., 2006). Contrastingly, both cell proliferation and neuronal survival in the DG were reduced after psychosocial stress exposure, as observed in a dominant-subordinate model in tree-shrews (Gould et al., 1997, 1998), or after exposure to predator cues in rats (Tanapat et al., 2001). In mice, acute restraint stress triggered an increase in cell proliferation (Bain et al., 2004), while social stress inhibited proliferation in the hippocampus (Mitra et al., 2006). In our 
study, hippocampal cell proliferation was unchanged after chronic exposure to restraint stress, but the number of newly generated cells detected after $21 \mathrm{~d}$ of chronic stress exposure was reduced. Differences in stress-induced glutamate excitoxicity (Reagan et al., 2004) or BDNF expression (Smith et al., 1995) may underlie the stress-dependent effects on new cell generation. Alternatively, physiological habituation to the stressor, habituation of the proliferation process after $21 \mathrm{~d}$, or a reduced sensitivity to glucocorticoids could be involved (Magariños and McEwen, 1995; Czéh et al., 2002). Moreover, stressor- and speciesdependent differences in the local neuronal release of protective factors, including PRL (Shingo et al., 2003; Torner et al., 2004), may contribute to the diversity of stress effects on hippocampal neurogenesis.

Cell fate integrates all cellular events occurring from regional proliferation, migration and differentiation. The present data suggest that exposure to chronic stress results in a decrease in hippocampal neurogenesis, as demonstrated previously (Magariños and McEwen, 1995; Czéh et al., 2002; Kaneko et al., 2006). A limited number of endogenous molecules, such as glucocorticoids or estrogens, have been identified as modulators of neurogenesis to date (Ming and Song, 2005; Sundberg et al., 2006). In mice, both systemic and intracerebral PRL treatment has been shown to increase cell proliferation in SVZ, but not in the hippocampal DG, under stress-free conditions (Shingo et al., 2003). Importantly, our results extend these findings by demonstrating that daily PRL treatment prevents the decrease in hippocampal cell numbers after 3 weeks of chronic stress. Although experimental evidence is still lacking, the protective action of PRL may be mediated via effects on proliferation at an earlier stage of the stress procedure, on cell fate decision or on apoptosis within the DG. Importantly, in the SVZ PRL receptors were identified in germinal neurospheres, indicating a direct local effect of PRL on cell proliferation (Shingo et al., 2003).

PRL might promote cell differentiation into neurons in vivo, as we found a higher percentage of newborn neurons in the DG of stressed, PRL-treated mice. In support, PRL promotes cell differentiation in cultured embryonic astrocytes (Mangoura et al., 2000), and induces cell maturation of $\mathrm{B}$ cells in an estrogen-dependent manner (Cohen-Solal et al., 2006). In the present studies, PRL treatment significantly reduced the percentage of GFAP-expressing cells in both control and stressed mice. Recent reports showed that GFAP-expressing SVZ astrocytes serve as primary precursors of new neurons (Doetsch et al., 1999). Thus, it is tempting to speculate that PRL might selectively promote neuronal fate via the differentiation of cell precursors to astrocytes, which in turn develop into new neurons under stress conditions.

Alternatively, PRL might enhance cell proliferation in the DG under selective circumstances (i.e., enhancing growth factor proliferative effects), and/or promote neuroprotective (antiapoptotic) mechanisms in the mouse hippocampus during chronic stress. Indeed, a role of PRL as a proliferative and/or antiapoptotic factor has been documented in several cell types (Naylor et al., 2003; Scarabelli et al., 2003; Asai-Sato et al., 2005). In detail, proliferative effects of PRL were observed in neuroblastoma (Mohammad et al., 2002), PC12 (Cheng et al., 2000) and oligodendrocyte precursor cells (Gregg et al., 2007), as well as in embryonic astrocytes, where it promotes both proliferation and differentiation (Mangoura et al., 2000). Furthermore, PRL decreases apoptosis in glucocorticoid-treated lymphocytes (Krishnan et al., 2003) or Nb2 lymphoma cells (Leff et al., 1996), mediated in part by increasing the expression of the antiapoptotic protein $\mathrm{Bcl}-2$ while decreasing the expression of the proapoptotic
Bax (Leff et al., 1996). Moreover, the proto-oncogene pim-1, which is associated with proliferation and nearly absent in quiescent cells, is upregulated by PRL in Nb2-11 lymphoma cells (Murphy et al., 1988; Buckley et al., 1995). Thus, further studies are required to investigate the detailed cellular and molecular mechanisms of PRL action in the hippocampus in the context of chronic stress.

Although previous studies have demonstrated the presence of the PRL receptors in the hippocampus (Roky et al., 1994; Mustafa et al., 1994; Nogami et al., 2007), controversy was recently raised as to whether PRL receptor mRNA is indeed expressed in hippocampal tissue (Mak et al., 2007). Here, we provide clear evidence that both the long and short isoforms of the PRL receptor are expressed in hippocampal tissue of mice (Fig. 5).

The presence of PRL receptors in the hippocampus suggests a direct action of PRL on processes of hippocampal neurogenesis rather than indirect effects on stress-related systemic factors. Established stress-related parameters (Rai et al., 2003; Reber et al., 2006, 2007) were found to be altered by chronic stress exposure, but were independent of PRL treatment. In detail, daily exposure to restraint stress over $21 \mathrm{~d}$ resulted in significantly decreased body weight gain, increased adrenal weights and lower thymus weights in both vehicle- and PRL-treated mice to a similar extent compared with nonstressed controls. Moreover, both vehicleand PRL-treated chronically stressed mice showed comparably high basal plasma corticosterone concentrations on day 4 of stressor exposure.

As discussed above, elevated glucocorticoid levels are known to be a main factor associated with the reduction of hippocampal cell proliferation and survival (Gould et al., 1992; Czéh et al., 2002). In this context, it is important to mention that the brain PRL system is involved in the regulation of the hypothalamopituitary-adrenal (HPA) axis (re)activity as shown in lactating (Torner et al., 2002) and nonlactating (Donner et al., 2007) female rats. For example, chronic infusion of PRL into the lateral ventricle attenuated the acute stress-induced rise in hypothalamic corticotrophin releasing hormone mRNA expression and in plasma noradrenaline and corticosterone (Donner et al., 2007). However, peripheral PRL administration in chronically stressed mice, as in the present study, was not effective in altering systemic stress parameters including plasma glucocorticoid concentrations (Fig. 6). Therefore, it is unlikely that the finding of PRL-induced rescue of hippocampal neurogenesis under chronic stress conditions in male mice is due to the inhibition of corticosterone stress responses, supporting a rather direct effect of PRL within the hippocampus.

The functional significance of PRL-stimulated neuronal survival in the hippocampus during chronic stress is unknown. In addition to peripheral PRL secretion, the brain PRL system is activated (Pi and Grattan, 1999; Torner et al., 2004) under conditions of elevated plasma glucocorticoids, i.e., during stress as well as in the peripartum period (Stern et al., 1973; Bonnin, 1992; Walker et al., 1992, Leuner et al., 2007). Thus, intracerebral PRL may be an important local contributor to counteract the detrimental effects of glucocorticoids on hippocampal neurogenesis via PRL receptor-mediated mechanisms. Recently, a decreased number of proliferating cells has been reported in the hippocampus of lactating rats, a finding which was linked to high glucocorticoid levels (Leuner et al., 2007). It needs to be shown, if high brain PRL levels could ameliorate further damage of hippocampal neurogenesis during lactation, for example in response to additional stressful stimuli. In support, it has been shown that lactation protects against the excitotoxic damage induced by 
kainic acid in hippocampal areas (Vanoye-Carlo et al., 2008). Reproductive experience also affects adult neurogenesis in the neural circuit underlying maternal behavior (Akbari et al., 2007).

In addition, a possible link exists between PRL, hippocampal neurogenesis and mood disorders. Brain PRL receptors were shown to mediate the anxiolytic effect of PRL (Torner et al., 2001), and a reduced state anxiety has been reported in lactation (Carter and Altemus, 2001; Heinrichs et al., 2001; Neumann, 2001; Lonstein, 2005; Leuner et al., 2007), which is partially mediated by PRL (Torner et al., 2002). Furthermore, women with postpartum depression were shown to have lower circulating PRL concentrations (Abou-Saleh et al., 1998). Thus, given the evidence of a link between hippocampal neurogenesis and mood disorders (Santarelli et al., 2003; Vollmayr et al., 2007), PRL is likely to contribute to the fine-tuned balance of stress responsiveness and hippocampal neurogenesis in both sexes. Moreover, these effects would ensure appropriate emotional and maternal responses in the postpartum period despite the dramatic fluctuations in sexual steroids.

In conclusion, PRL exerts protective effects on adult neurogenesis in the hippocampal DG under chronic stress conditions. Daily PRL treatment prevented the stress-induced decrease in hippocampal cell survival without affecting proliferation. Moreover, PRL promotes a neuronal fate of newly generated cells in stressed mice and, therefore, seems to be a survival factor for neurons within the hippocampus.

\section{References}

Abou-Saleh MT, Ghubash R, Karim L, Krymski M, Bhai I (1998) Hormonal aspects of postpartum depression. Psychoneuroendocrinology 23:465-475.

Akbari EM, Chatterjee D, Lévy F, Fleming AS (2007) Experience-dependent cell survival in the maternal rat brain. Behav Neurosci 121:1001-1011.

Asai-Sato M, Nagashima Y, Miyagi E, Sato K, Ohta I, Vonderhaar BK, Hirahara F (2005) Prolactin inhibits apoptosis of ovarian carcinoma cells induced by serum starvation or cisplatin treatment. Int $\mathrm{J}$ Cancer 115:539-544.

Bain MJ, Dwyer SM, Rusak B (2004) Restraint stress affects hippocampal cell proliferation differently in rats and mice. Neurosci Lett 368:7-10.

Ben-Jonathan N, Mershon JL, Allen DL, Steinmetz RW (1996) Extrapituitary prolactin: distribution, regulation, functions, and clinical aspects. Endocr Rev 17:639-669.

Biebl M, Cooper CM, Winkler J, Kuhn HG (2000) Analysis of neurogenesis and programmed cell death reveals a self-renewing capacity in the adult rat brain. Neurosci Lett 291:17-20.

Bonnin F (1992) Cortisol levels in saliva and mood changes in early puerperium. J Affect Disord 26:231-239.

Bridges RS, Numan M, Ronsheim PM, Mann PE, Lupini CE (1990) Central prolactin infusions stimulate maternal behavior in steroid-treated nulliparous female rats. Proc Natl Acad Sci U S A 87:8003-8007.

Buckley AR, Buckley DJ, Leff MA, Hoover DS, Magnuson NS (1995) Rapid induction of pim-1 expression by prolactin and interleukin-2 in rat $\mathrm{Nb} 2$ lymphoma cells. Endocrinology 136:5252-5259.

Cameron HA, Gould E (1994) Adult neurogenesis is regulated by adrenal steroids in the dentate gyrus. Neuroscience 61:203-209.

Cameron HA, Woolley CS, McEwen BS, Gould E (1993) Differentiation of newly born neurons and glia in the dentate gyrus of the adult rat. Neuroscience 56:337-344.

Carter CS, Altemus M (2001) Integrative functions of lactational hormones in social behavior and stress management. Ann NY Acad Sci 807:164-174

Cheng Y, Zhizhin I, Perlman RL, Mangoura D (2000) Prolactin-induced cell proliferation in PC12 cells depends on JNK but not ERK activation. J Biol Chem 275:23326-23332.

Clapp C, Torner L, Gutiérrez-Ospina G, Alcántara E, López-Gómez FJ, Nagano M, Kelly PA, Mejía S, Morales MA, Martínez de la Escalera G (1994) The prolactin gene is expressed in the hypothalamic-neurohypophyseal system and the protein is processed into a $14-\mathrm{kDa}$ fragment with activity like 16-kDa prolactin. Proc Natl Acad Sci U S A 91:10384-10388.
Cohen-Solal JF, Jeganathan V, Grimaldi CM, Peeva E, Diamond B (2006) Sex hormones and SLE: influencing the fate of autoreactive B cells. Curr Top Microbiol Immunol 305:67-88.

Czéh B, Welt T, Fischer AK, Erhardt A, Schmitt W, Müller MB, Toschi N, Fuchs E, Keck ME (2002) Chronic psychosocial stress and concomitant repetitive transcranial magnetic stimulation: effects on stress hormone levels and adult hippocampal neurogenesis. Biol Psychiatry 52:1057-1065.

DeVito WJ, Stone S, Avakian C (1991) Stimulation of hypothalamic prolactin release by veratridine and angiotensin II in the female rat: effect of ovariectomy and estradiol administration. Neuroendocrinology 54:391-398.

DeVito WJ, Okulicz WC, Stone S, Avakian C (1992) Prolactin-stimulated mitogenesis of cultured astrocytes. Endocrinology 130:2549-2556.

Doetsch F, Caillé I, Lim DA, García-Verdugo JM, Alvarez-Buylla A (1999) Subventricular zone astrocytes are neural stem cells in the adult mammalian brain. Cell 97:703-716.

Donner N, Bredewold R, Maloumby R, Neumann ID (2007) Chronic intracerebral prolactin attenuates neuronal stress circuitries in virgin rats. Eur J Neurosci 25:1804-1814.

Duman RS, Malberg J, Nakagawa S (2001) Regulation of adult neurogenesis by psychotropic drugs and stress. J Pharmacol Exp Ther 299:401-407.

Eriksson PS, Perfilieva E, Björk-Eriksson T, Alborn AM, Nordborg C, Peterson DA, Gage FH (1998) Neurogenesis in the adult human hippocampus. Nat Med 4:1313-1317.

Fujikawa T, Soya H, Tamashiro KL, Sakai RR, McEwen BS, Nakai N, Ogata M, Suzuki I, Nakashima K (2004) Prolactin prevents acute stress-induced hypocalcemia and ulcerogenesis by acting in the brain of rat. Endocrinology 145:2006-2013.

Gould E, Cameron HA, Daniels DC, Woolley CS, McEwen BS (1992) Adrenal hormones suppress cell division in the adult rat dentate gyrus. J Neurosci 12:3642-3650.

Gould E, McEwen BS, Tanapat P, Galea LA, Fuchs E (1997) Neurogenesis in the dentate gyrus of the adult tree shrew is regulated by psychosocial stress and NMDA receptor activation. J Neurosci 17:2492-2498.

Gould E, Tanapat P, McEwen BS, Flügge G, Fuchs E (1998) Proliferation of granule cell precursors in the dentate gyrus of adult monkeys is diminished by stress. Proc Natl Acad Sci U S A 95:3168-3171.

Gregg C, Shikar V, Larsen P, Mak G, Chojnacki A, Yong VW, Weiss S (2007) White matter plasticity and enhanced remyelination in the maternal CNS. J Neurosci 27:1812-1823.

Heine VM, Maslam S, Zareno J, Joëls M, Lucassen PJ (2004) Suppressed proliferation and apoptotic changes in the rat dentate gyrus after acute and chronic stress are reversible. Eur J Neurosci 19:131-144.

Heinrichs M, Meinlschmidt G, Neumann ID, Wagner S, Kirschbaum C, Ehlert U, Hellhammer DH (2001) Effects of suckling on hypothalamicpituitary-adrenal axis responses to psychosocial stress in postpartum lactating women. J Clin Endocrinol Metab 86:4978-4804.

Kaneko N, Okano H, Sawamoto K (2006) Role of the cholinergic system in regulating survival of newborn neurons in the adult mouse dentate gyrus and olfactory bulb. Genes Cells 11:1145-1159.

Kempermann G, Kuhn HG, Gage FH (1997) More hippocampal neurons in adult mice living in an enriched environment. Nature 386:493-495.

Kokay IC, Bull PM, Davis RL, Ludwig M, Grattan DR (2006) Expression of the long form of the prolactin receptor in magnocellular oxytocin neurons is associated with specific prolactin regulation of oxytocin neurons. Am J Physiol Regul Integr Comp Physiol 290:R1216-R1225.

Krishnan N, Thellin O, Buckley DJ, Horseman ND, Buckley AR (2003) Prolactin suppresses glucocorticoid-induced thymocyte apoptosis in vivo. Endocrinology 144:2102-2110.

Kuhn HG, Dickinson-Anson H, Gage FH (1996) Neurogenesis in the dentate gyrus of the adult rat: age-related decrease of neuronal progenitor proliferation. J Neurosci 16:2027-2033.

Larsen CM, Kokay IC, Grattan DR (2008) Male pheromones initiate prolactin-induced neurogenesis and advance maternal behavior in female mice. Horm Behav 53:509-517.

Lee KJ, Kim SJ, Kim SW, Choi SH, Shin YC, Park SH, Moon BH, Cho E, Lee MS, Choi SH, Chun BG, Shin KH (2006) Chronic mild stress decreases survival, but not proliferation, of new-born cells in adult rat hippocampus. Exp Mol Med 38:44-54.

Leff MA, Buckley DJ, Krumenacker JS, Reed JC, Miyashita T, Buckley AR (1996) Rapid modulation of the apoptosis regulatory genes, bcl-2 and 
bax by prolactin in rat $\mathrm{Nb} 2$ lymphoma cells. Endocrinology 137:5456-5462.

Leuner B, Mirescu C, Noiman L, Gould E (2007) Maternal experience inhibits the production of immature neurons in the hippocampus during the postpartum period through elevations in adrenal steroids. Hippocampus 17:434-442.

Lie DC, Song H, Colamarino SA, Ming GL, Gage FH (2004) Neurogenesis in the adult brain: new strategies for central nervous system diseases. Annu Rev Pharmacol Toxicol 44:399-421.

Lonstein JS (2005) Reduced anxiety in postpartum rats requires recent physical interactions with pups, but is independent of suckling and peripheral sources of hormones. Horm Behav 47:241-255.

Lucassen PJ, Vollmann-Honsdorf GK, Gleisberg M, Czéh B, De Kloet ER, Fuchs E (2001) Chronic psychosocial stress differentially affects apoptosis in hippocampal subregions and cortex of the adult tree shrew. Eur J Neurosci 14:161-166.

Magariños AM, McEwen BS (1995) Stress-induced atrophy of apical dendrites of hippocampal CA3c neurons: involvement of glucocorticoid secretion and excitatory amino acid receptors. Neuroscience 69:89-98.

Mak GK, Enwere EK, Gregg C, Pakarainen T, Poutanen M, Huhtaniemi I, Weiss S (2007) Male pheromone-stimulated neurogenesis in the adult female brain: possible role in mating behavior. Nat Neurosci 10:1003-1011.

Malberg JE (2004) Implications of adult hippocampal neurogenesis in antidepressant action. J Psychiatry Neurosci 29:196-205.

Mangoura D, Pelletiere C, Leung S, Sakellaridis N, Wang DX (2000) Prolactin concurrently activates src-PLD and JAK/Stat signaling pathways to induce proliferation while promoting differentiation in embryonic astrocytes. Int J Dev Neurosci 18:693-704.

Mangurian LP, Walsh RJ, Posner BI (1992) Prolactin enhancement of its own uptake at the choroid plexus. Endocrinology 131:698-702.

McEwen BS (2000) Effects of adverse experiences for brain structure and function. Biol Psychiatry 48:721-731.

Ming GL, Song H (2005) Adult neurogenesis in the mammalian central nervous system. Annu Rev Neurosci 28:223-250.

Mirescu C, Gould E (2006) Stress and adult neurogenesis. Hippocampus 16:233-238.

Mitra R, Sundlass K, Parker KJ, Schatzberg AF, Lyons DM (2006) Social stress-related behavior affects hippocampal cell proliferation in mice. Physiol Behav 89:123-127.

Mohammad YN, Perone M, Wang L, Ingleton PM, Castro MG, Lovejoy DA (2002) Expression of prolactin receptors and regulation of cell proliferation by prolactin, corticotropin-releasing factor, and corticosterone in a neuroblastoma cell line. Biochem Cell Biol 80:475-482.

Murphy PR, DiMattia GE, Friesen HG (1988) Role of calcium in prolactinstimulated c-myc gene expression and mitogenesis in $\mathrm{Nb} 2$ lymphoma cells. Endocrinology 122:2476-2485.

Mustafa A, Nyberg F, Bogdanovic N, Islam A, Roos P, Adem A (1994) Somatogenic and lactogenic binding sites in rat brain and liver: quantitative autoradiographic localization. Neurosci Res 20:257-263.

Naylor MJ, Lockefeer JA, Horseman ND, Ormandy CJ (2003) Prolactin regulates mammary epithelial cell proliferation via autocrine/paracrine mechanism. Endocrine 20:111-114.

Neumann ID (2001) Alterations in behavioural and neuroendocrine stress coping strategies in pregnant, parturient and lactating rats. Prog Brain Res 133:143-152.

Nogami H, Hoshino R, Ogasawara K, Miyamoto S, Hisano S (2007) Regionspecific expression and hormonal regulation of the first exon variants of rat prolactin receptor mRNA in rat brain and anterior pituitary gland. J Neuroendocrinol 19:583-593.

Pham K, Nacher J, Hof PR, McEwen BS (2003) Repeated restraint stress suppresses neurogenesis and induces biphasic PSA-NCAM expression in the adult rat dentate gyrus. Eur J Neurosci 17:879-886.

Pi XJ, Grattan DR (1998) Distribution of prolactin receptor immunoreactivity in the brain of estrogen-treated, ovariectomized rats. J Comp Neurol 394:462-474.

Pi XJ, Grattan DR (1999) Increased expression of both short and long forms of prolactin receptor mRNA in hypothalamic nuclei of lactating rats. J Mol Endocrinol 23:13-22.

Rai D, Bhatia G, Sen T, Palit G (2003) Comparative study of perturbations of peripheral markers in different stressors in rats. Can J Physiol Pharmacol 81:1139-1146.
Reagan LP, Rosell DR, Wood GE, Spedding M, Muñoz C, Rothstein J, McEwen BS (2004) Chronic restraint stress up-regulates GLT-1 mRNA and protein expression in the rat hippocampus: reversal by tianeptine. Proc Natl Acad Sci U S A 101:2179-2184.

Reber SO, Obermeier F, Straub RH, Straub HR, Falk W, Neumann ID (2006) Chronic intermittent psychosocial stress (social defeat/overcrowding) in mice increases the severity of an acute DSS-induced colitis and impairs regeneration. Endocrinology 147:4968-4976.

Reber SO, Birkeneder L, Veenema AH, Obermeier F, Falk W, Straub RH, Neumann ID (2007) Adrenal insufficiency and colonic inflammation after a novel chronic psycho-social stress paradigm in mice: implications and mechanisms. Endocrinology 148:670-682.

Roky R, Valatx JL, Paut-Pagano L, Jouvet M (1994) Hypothalamic injection of prolactin or ist antibody alters the rat sleep-wake cycle. Physiol Behav 55:1015-1019.

Santarelli L, Saxe M, Gross C, Surget A, Battaglia F, Dulawa S, Weisstaub N, Lee J, Duman R, Arancio O, Belzung C, Hen R (2003) Requirement of hippocampal neurogenesis for the behavioral effects of antidepressants. Science 301:805-809.

Scarabelli L, Caviglia D, Bottazzi C, Palmero S (2003) Prolactin effect on pre-pubertal Sertoli cell proliferation and metabolism. J Endocrinol Invest $26: 718-722$.

Shingo T, Gregg C, Enwere E, Fujikawa H, Hassam R, Geary C, Cross JC, Weiss S (2003) Pregnancy-stimulated neurogenesis in the adult female forebrain mediated by prolactin. Science 299:117-120.

Smith MA, Makino S, Kvetnansky R, Post RM (1995) Stress alters the expression of brain-derived neurotrophic factor and neurotrophin-3 mRNAs in the hippocampus. J Neurosci 15:1768-1777.

Stern JM, Goldman L, Levine S (1973) Pituitary-adrenal responses during lactation in rats. Neuroendocrinology 12:179-191.

Sundberg M, Savola S, Hienola A, Korhonen L, Lindholm D (2006) Glucocorticoid hormones decrease proliferation of embryonic neural stem cells through ubiquitin-mediated degradation of cyclin D1. J Neurosci 26:5402-5410.

Takahashi T, Nowakowski RS, Caviness VS Jr (1992) BUdR as an S-phase marker for quantitative studies of cytokinetic behaviour in the murine cerebral ventricular zone. J Neurocytol 21:185-197.

Tanapat P, Hastings NB, Rydel TA, Galea LA, Gould E (2001) Exposure to fox odor inhibits cell proliferation in the hippocampus of adult rats via an adrenal hormone-dependent mechanism. J Comp Neurol 437:496-504.

Torner L, Mejía S, López-Gómez FJ, Quintanar A, Martínez de la Escalera G, Clapp C (1995) A 14-kilodalton prolactin-like fragment is secreted by the hypothalamo-neurohypophyseal system of the rat. Endocrinology 136:5454-5460.

Torner L, Toschi N, Pohlinger A, Landgraf R, Neumann ID (2001) Anxiolytic and anti-stress effects of brain prolactin: improved efficacy of antisense targeting of the prolactin receptor by molecular modeling. J Neurosci 21:3207-3214.

Torner L, Toschi N, Nava G, Clapp C, Neumann ID (2002) Increased hypothalamic expression of prolactin in lactation: involvement in behavioural and neuroendocrine stress responses. Eur J Neurosci 15:1381-1389.

Torner L, Maloumby R, Nava G, Aranda J, Clapp C, Neumann ID (2004) In vivo release and gene upregulation of brain prolactin in response to physiological stimuli. Eur J Neurosci 19:1601-1608.

Vanoye-Carlo A, Morales T, Ramos E, Mendoza-Rodríguez A, Cerbón M (2008) Neuroprotective effects of lactation against kainic acid treatment in the dorsal hippocampus of the rat. Horm Behav 53:112-123.

Vollmayr B, Mahlstedt MM, Henn FA (2007) Neurogenesis and depression: what animal models tell us about the link. Eur Arch Psychiatry Clin Neurosci 257:300-303.

Walker CD, Lightman SL, Steele MK, Dallman MF (1992) Suckling is a persistent stimulus to the adrenocortical system of the rat. Endocrinology 130:115-125.

Walsh RJ, Slaby FJ, Posner BI (1987) A receptor-mediated mechanism for the transport of prolactin from blood to cerebrospinal fluid. Endocrinology 120:1846-1850.

Winner B, Lie DC, Rockenstein E, Aigner R, Aigner L, Masliah E, Kuhn HG, Winkler J (2004) Human wild-type alpha synuclein impairs neurogenesis. J Neuropathol Exp Neurol 63:1155-1166.

Winner B, Rockenstein E, Lie DC, Aigner R, Mante M, Bogdahn U, CouillardDespres S, Masliah E, Winkler J (2008) Mutant alpha-synuclein exacerbates age-related decrease of neurogenesis. Neurobiol Aging 29:913-925. 